\title{
Correlation Analysis of Spatial Distribution, Temporal Seismotectonics, and Return Period of Earthquake in East Nusa Tenggara, Indonesia
}

\author{
Hery Leo Sianturi $\mathbb{D},{ }^{1,2}$ Adi Susilo, ${ }^{3}$ Sunaryo, ${ }^{3}$ and Sukir Maryanto $\mathbb{D}^{3}$ \\ ${ }^{1}$ Graduate School of Environmental Science, University of Brawijaya Malang, East Java, Indonesia \\ ${ }^{2}$ Department of Physics, University of Nusa Cendana, East Nusa Tenggara, Indonesia \\ ${ }^{3}$ Department of Physics, Faculty of Mathematics and Natural Sciences, University of Brawijaya, Malang, East Java, Indonesia \\ Correspondence should be addressed to Hery Leo Sianturi; hery9n2ri.hls@gmail.com
}

Received 19 February 2019; Revised 17 May 2019; Accepted 9 June 2019; Published 10 July 2019

Academic Editor: Yun-tai Chen

Copyright (C) 2019 Hery Leo Sianturi et al. This is an open access article distributed under the Creative Commons Attribution License, which permits unrestricted use, distribution, and reproduction in any medium, provided the original work is properly cited.

\begin{abstract}
This paper presents spatial distribution, temporal seismotectonics, and return period of earthquake in East Nusa Tenggara Province, Indonesia, using earthquake data and Maximum Likelihood methods. The data used are ISC, USGS/NEIC, and Indonesian Meteorology, Climatology and Geophysics Agency (IMCGA) earthquake catalog data for the period of 1918 to 2015 . The results show that the a-value ranges from 5.0 to 8.5 and b-value ranges from 0.6 to 1.3 . The pattern of spatial distribution of $b$-value is relatively low corresponding to the low of a-value, which means the high level of stress of rock in the area. The fractal dimension shows that the D value ranges from 1.384 to 1.874. The earthquake that occurred in East Nusa Tenggara Province was dominated by a small magnitude with great seismicity and the fastest return period is in Alor and Timor islands which is 44 days.
\end{abstract}

\section{Introduction}

East Nusa Tenggara Province (ENTP) is one of the areas where the frequency of earthquake occurrences is high. There are about 4,162 tectonic earthquakes occurring in this area in the period of 1918 to 2015 (Figure 1). This is due to Australian plate subduction to Eurasian plates just below ENTP region and some local fault around ENTP region [1-4].

Natural hazards such as tectonics earthquake are often devastating in terms of loss of life and environmental damage. The occurrence of the earthquake is not preventable, but its effect can be minimized through effective prevention and reduction of vulnerability. An earthquake can be predicted through approaches by using various methods with a number of pieces of sophisticated earthquake detection equipment, for example, the calculation of seismicity with the calculation of b-value and the return period of earthquake. The earthquake distribution can be indirectly considered as a fractal (D) that describes seismicity with tectonic parameters (bvalue).
One effort to find out the disaster-vulnerable areas from earthquake is by understanding the fault pattern by analyzing the previous earthquakes and calculating the earthquake precursor based on the results of spatial and temporal analysis using $b$-value and the return period of earthquakes.

$b$-Value Parameter. The relationship between number of earthquake and magnitude is determined by (1) [5].

$$
\log N=a-b m
$$

and

$$
N=10^{a-b m}
$$

In certain areas and interval time, (1) describe the number of earthquake $(\mathrm{N})$ with magnitude $(\mathrm{m})$, a is seismic activity constant, determined by scene that depends on determination of the volume and time window (time period), and b is tectonics parameter showing the characteristics of the medium with reference to stress or condition of local materials. b-value 


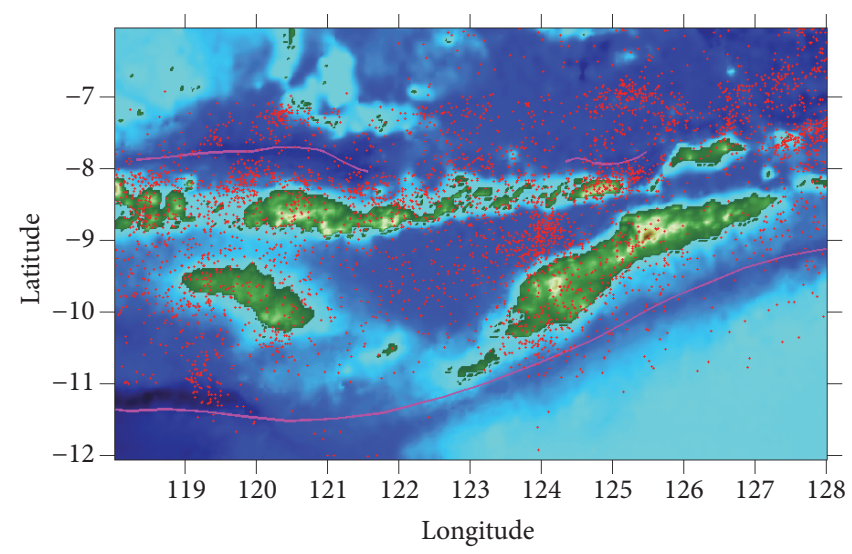

FIGURE 1: Earthquake distribution map in ENTP region from 1918 to 2015.

statistically can be calculated by using Utsu formula [6], called Maximum Likelihood Estimation (MLE) method:

$$
b=\frac{1}{\bar{m}-m_{\min }} \log 10^{e}
$$

and

$$
\bar{m}=\frac{\sum_{i=1}^{n} m_{i}}{n}
$$

$\bar{m}$ is average magnitude, $m_{\min }$ is minimum magnitude, and $n$ is the total number of earthquake data used to calculate bvalue.

Utsu [4] pointed out that the MLE method is better than the least square method, especially for data with a small number of earthquake $(\mathrm{N})$ events. The confidence interval for a given probability $(\mathrm{Pr})$ is

$$
b\left(1-\frac{1,960}{N}\right) \leq P_{r} \leq b\left(1+\frac{1,960}{N}\right)
$$

Equation (5) gives a probability of 95\%. The degree of certainty of b-value according to Shi and Bolt [7] is

$$
\sigma(b)=2.30 b^{2} \sqrt{\sum_{i=1}^{n} \frac{\left(m_{i}-\bar{m}\right)^{2}}{n(n-1)}}
$$

The relationship between the b-value and the fractal dimension, D, has a positive correlation and is expressed in (7) [8]:

$$
D=\frac{3 b}{c}
$$

$\mathrm{D}$ is fractal dimension, $\mathrm{b}$ is b-value of Guttenberg-Richter relation, and $c$ is constants that depend on the relative duration of the seismic source and the time constant of the recording system. For crystal stones, the $\mathrm{c}$ value is considered 3.0 , for the subduction zone $(100-700 \mathrm{~km})$ it is suggested to be 2.4 , and for most studies of the earthquake it is suggested to be $1.5[6]$.

Return Periods of Earthquake. The number of earthquakes per year is theoretically calculated by dividing the a-value by the observation period $(\mathrm{T})$.

$$
a_{1}=\frac{a}{\log T}
$$

The number of cumulative frequencies of earthquake per year or called the seismicity index is

$$
N_{1}(m)=10^{a_{1}-b m}
$$

The occurrence probability of one or more earthquakes greater than $\mathrm{m}$ in period $\mathrm{T}$ can be formulated as

$$
P(m, T)=\left(1-e^{-N(m) \cdot T}\right)
$$

Given $\mathrm{N}_{1}(\mathrm{~m})$, the mean value of return periods of damaging earthquake can be calculated:

$$
\theta=\frac{1}{N_{1}(m)} \text { years }
$$

\section{Materials and Methods}

Tectonic earthquake data were obtained from the catalog of International Seismological Center (ISC), United States Geological Survey (USGS), and Indonesian Meteorology, Climatology and Geophysics Agency (IMCGA) with depth of $\leq 600 \mathrm{~km}$ and magnitude of $\mathrm{mb} \geq 3$ in the study area $118^{\circ}$ $\mathrm{E}-128^{\circ} \mathrm{E}$ and $6^{\circ} \mathrm{S}-12^{\circ} \mathrm{S}$. The number of data obtained from the catalog is 4,162 events.

Based on the existence of fault, the study area is divided into 3 clusters (Figure 2), namely:

(i) Cluster 1: $6^{\circ} \mathrm{S}-9^{\circ} \mathrm{S}$ and $118^{\circ} \mathrm{E}-122,5^{\circ} \mathrm{E}$ (Flores island, Labuan Bajo, and surrounding areas)

(ii) Cluster 2: $6^{\circ} \mathrm{S}-12^{\circ} \mathrm{S}$ and $122,5^{\circ} \mathrm{E}-128^{\circ} \mathrm{E}$ (Alor island, Timor island, and surrounding areas)

(iii) Cluster 3: $9^{\circ} \mathrm{S}-12^{\circ} \mathrm{S}$ and $118^{\circ} \mathrm{E}-122,5^{\circ} \mathrm{E}$ (Sumba island and surrounding areas)

The data are processed with Microsoft Excel, ArcGis 9.3, and ZMAP 6.0 software using declustering according to Gardner and Knopoff method to obtain the main earthquakes. The main earthquakes were then processed to obtain the seismicity map (b-value and a-value) using Maximum Likelihood method and map variation of $b$-value spatially and temporally in ENTP and surrounding areas for each cluster. The flowchart of research can be seen in Figure 3. 


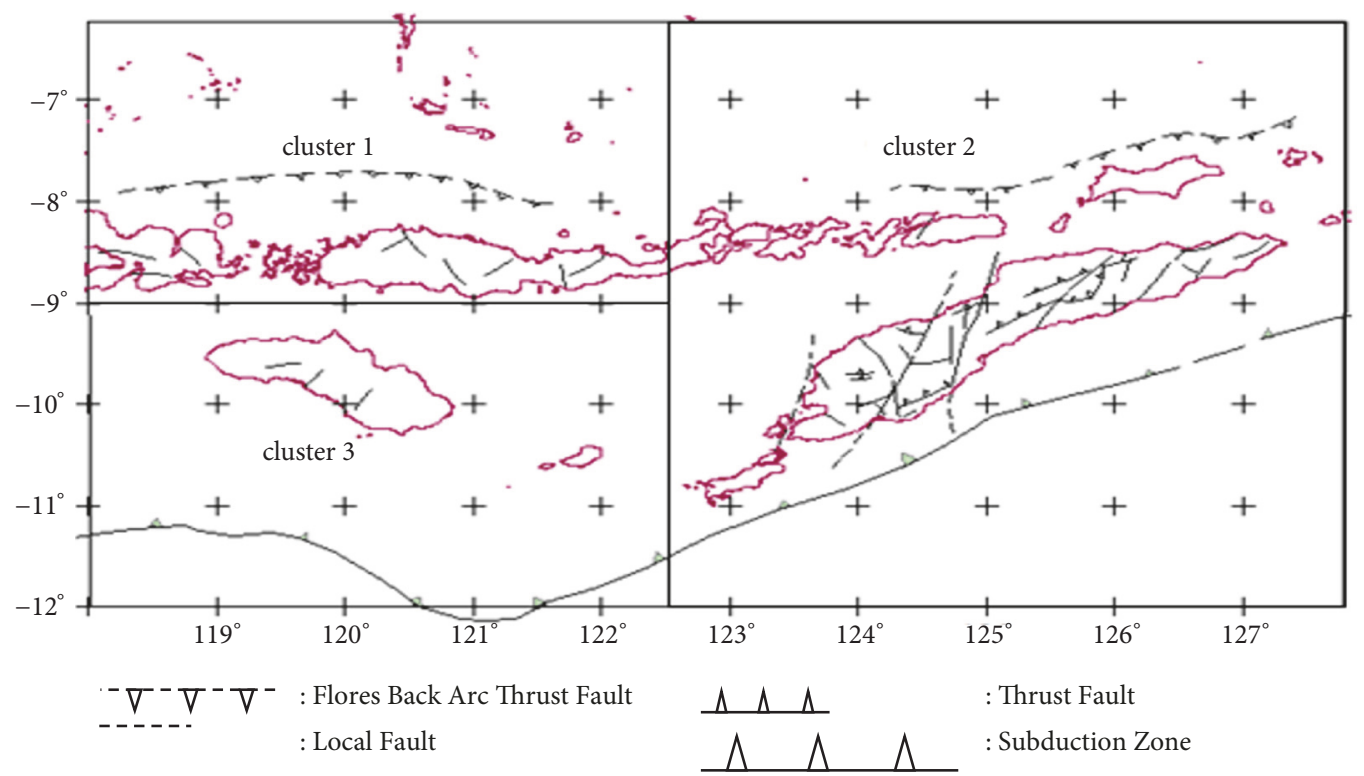

FIGURE 2: Clusters distribution of ENTP and surrounding areas used to find the differences of b-value for each region.

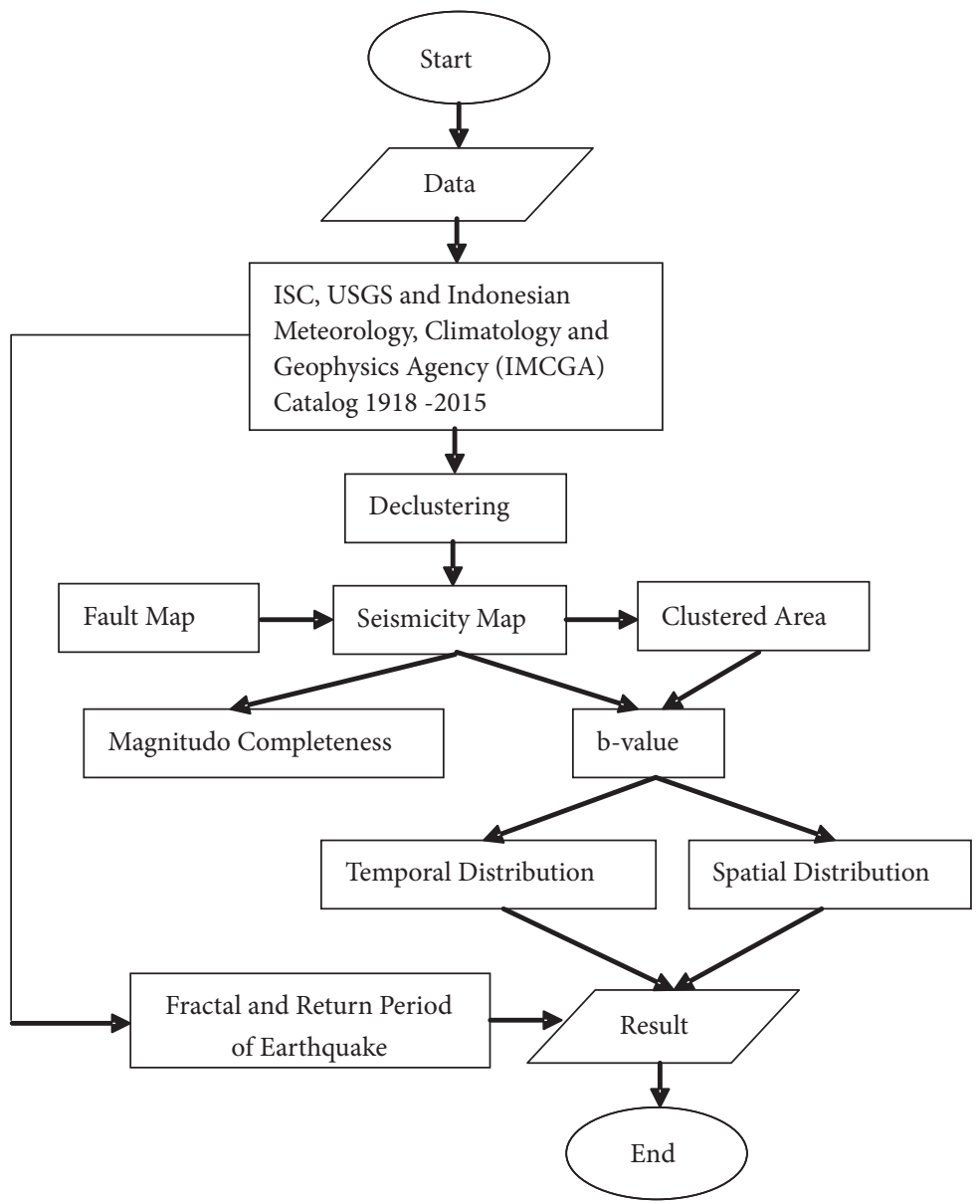

FIGURE 3: Flowchart of the research. 

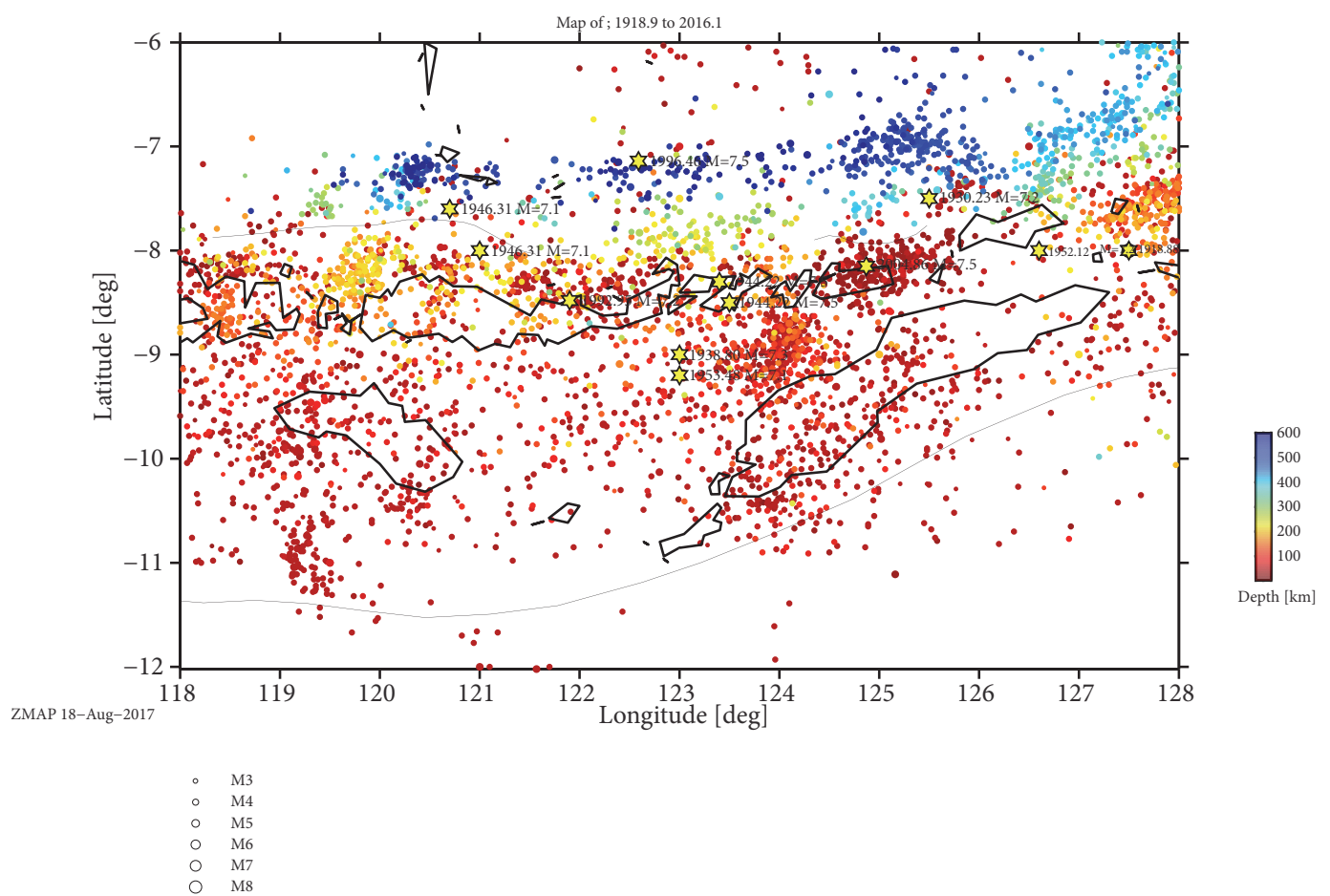

FIGURE 4: Earthquake seismicity map in ENTP showing depth and magnitude using ZMAP 6.0.
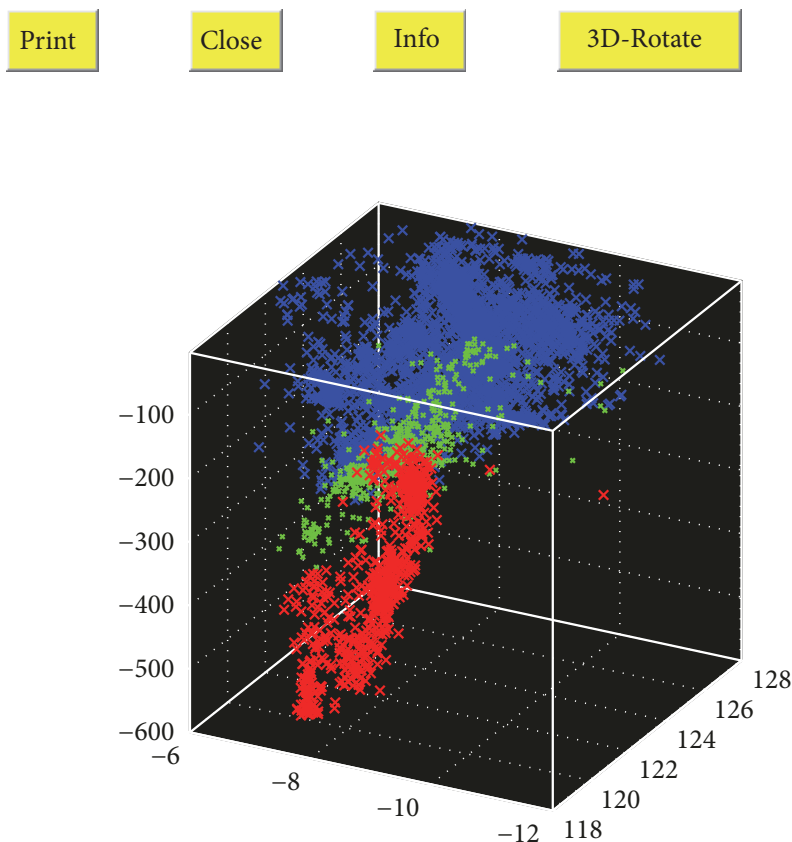

FIGURE 5: The 3-dimension map of earthquake distribution in ENTP using ZMAP 6.0.

\section{Results}

The earthquake in ENTP generally occurred at shallow depth $(<50 \mathrm{~km})$ around the Timor island, moderate depth $(50-$ $70 \mathrm{~km}$ ) around the ocean of Savu or between the Timor island and the Flores island, and deep $(>70 \mathrm{~km})$ around the Flores island (Figure 4).
The 3-dimension view of the earthquake distribution toward depth is presented in Figure 5. Meanwhile, the graphs of frequency-magnitude distribution along with magnitude completeness, a-value, and b-value distributions for all earthquake data are shown in Figures 6, 7(a), and 7(b).

Figure $7(a)$ shows that the a-values of the ENTP region range from 5 to 8.5 , indicating a fairly high level of seismicity. 


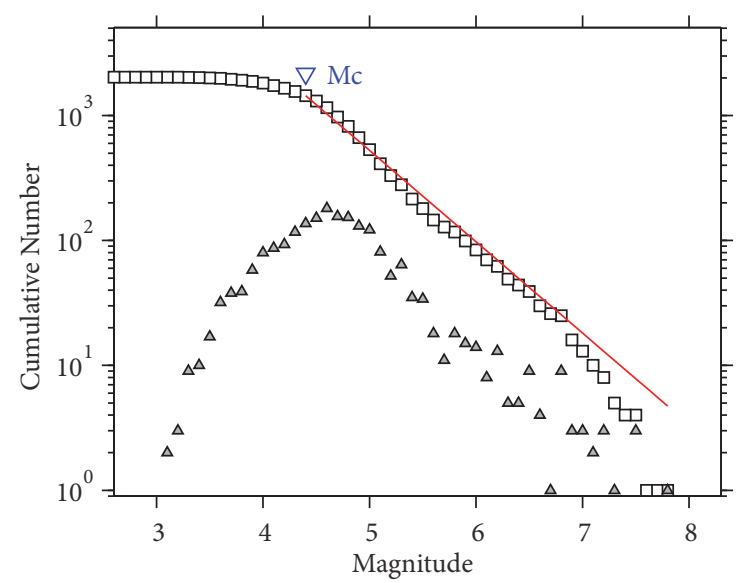

Maximum Likelihood Solution

$\mathrm{b}-$ value $=0.731+/-0.02$, a value $=6.38$, a value $($ annual $)=4.39$

Magnitude of Completeness $=4.4$

FIgURE 6: Magnitude distribution graph of seismicity in ENTP.

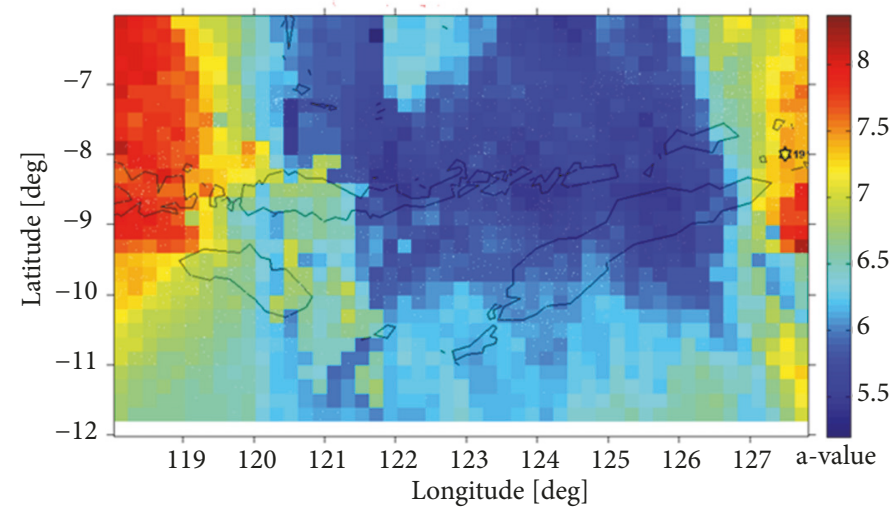

(a)

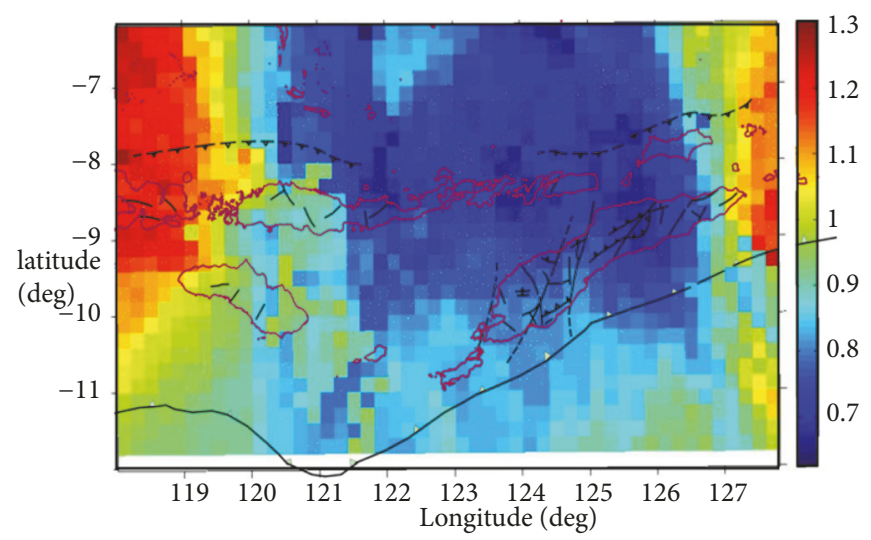

(b)

FIGURE 7: Spatial variation map of (a) a-values and (b) b-values for all earthquakes in ENTP.

Figure 7(b) shows that the b-values vary from 0.6 to 1.3 . This indicates that homogeneous rock types are relatively distributed equally across ENTP and are transported between Flores and Timor or around the Savu sea with the b-value about 0.7. This shows a high level of stress and relatively homogeneous. It is estimated that this could be caused by the faults found in the Timor island, extended toward the Savu sea. It is also due to the subduction of the Australian plate under the Eurasian plate just below the Timor island.

Based on temporal variation of b-values (Figure 8), it is found that there was a significant decline of $\mathrm{b}$-value prior to the occurrence of strong magnitude earthquakes of 7.5 in 


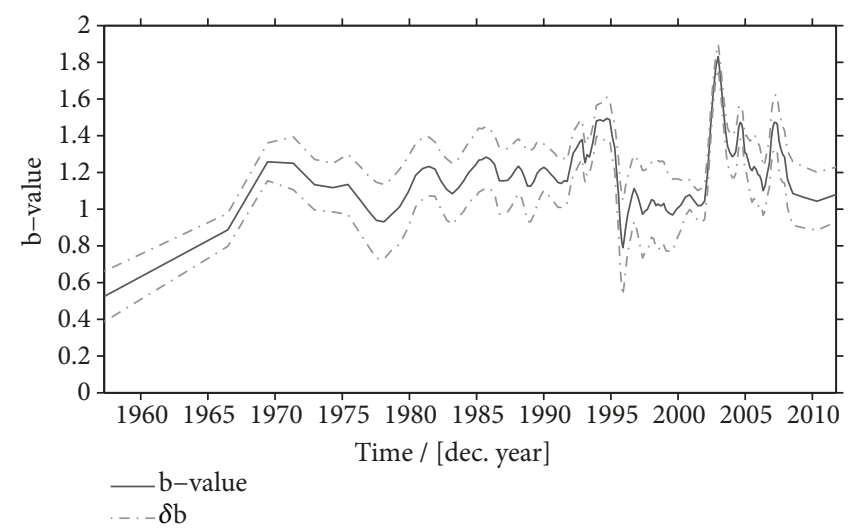

FIgURE 8: Temporal variation of b-value in ENTP region.

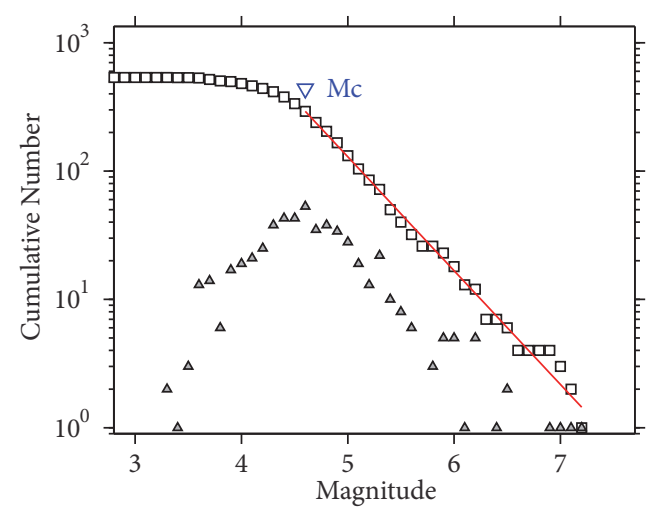

Maximum Likelihood Solution

$\mathrm{b}-$ value $=0.887+/-0.05$, a value $=6.54$, a value $($ annual $)=4.61$ Magnitude of Completeness $=4.6$

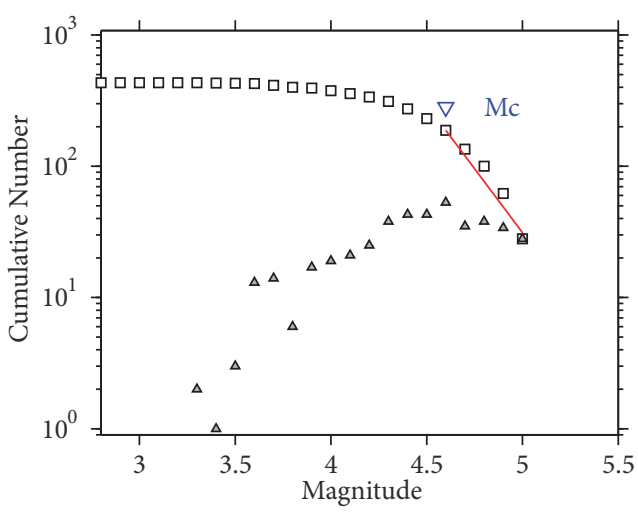

Maximum Likelihood Solution $\mathrm{b}-$ value $=1.95+/-0.09$, a value $=11.2$, a value $($ annual $)=9.52$ Magnitude of Completeness $=4.6$

(a)

(b)

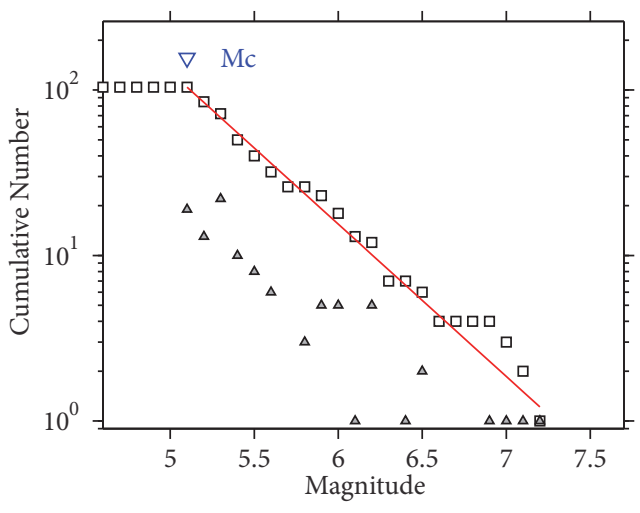

Maximum Likelihood Solution

$\mathrm{b}-$ value $=0.92+/-0.09$, a value $=6.71$, a value $($ annual $)=4.77$

Magnitude of Completeness $=5.1$

(c)

FIGURE 9: Magnitude distribution graph of seismicity for cluster 1 (Flores, Labuan Bajo, and surrounding areas): (a) for mb > 3 SR, (b) for $\mathrm{mb}=3-5 \mathrm{SR}$, and (c) for $\mathrm{mb}>5 \mathrm{SR}$. 


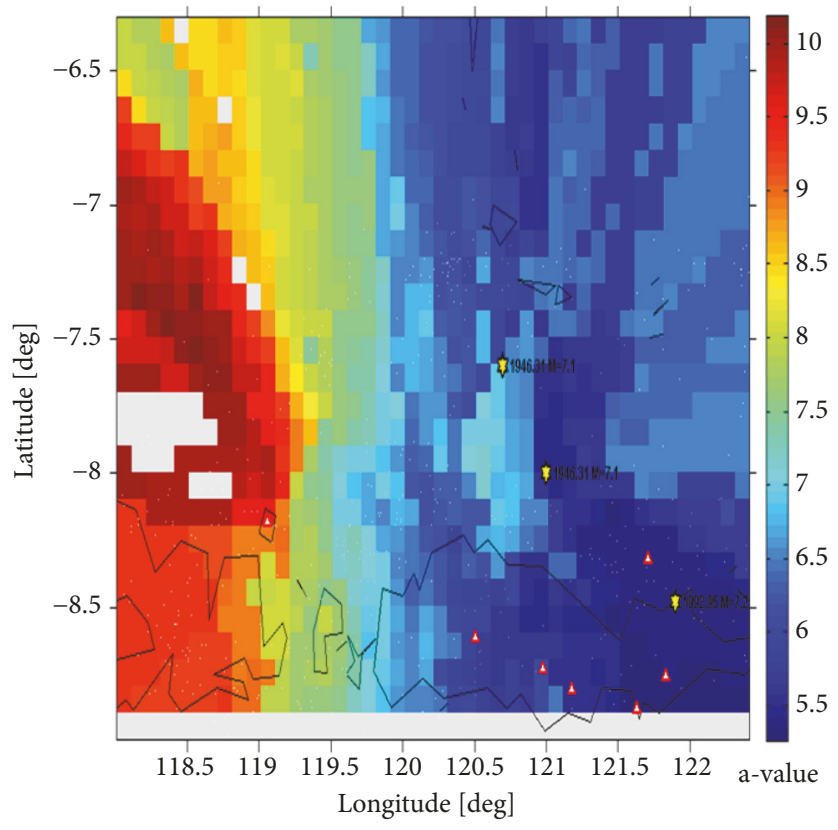

(a)

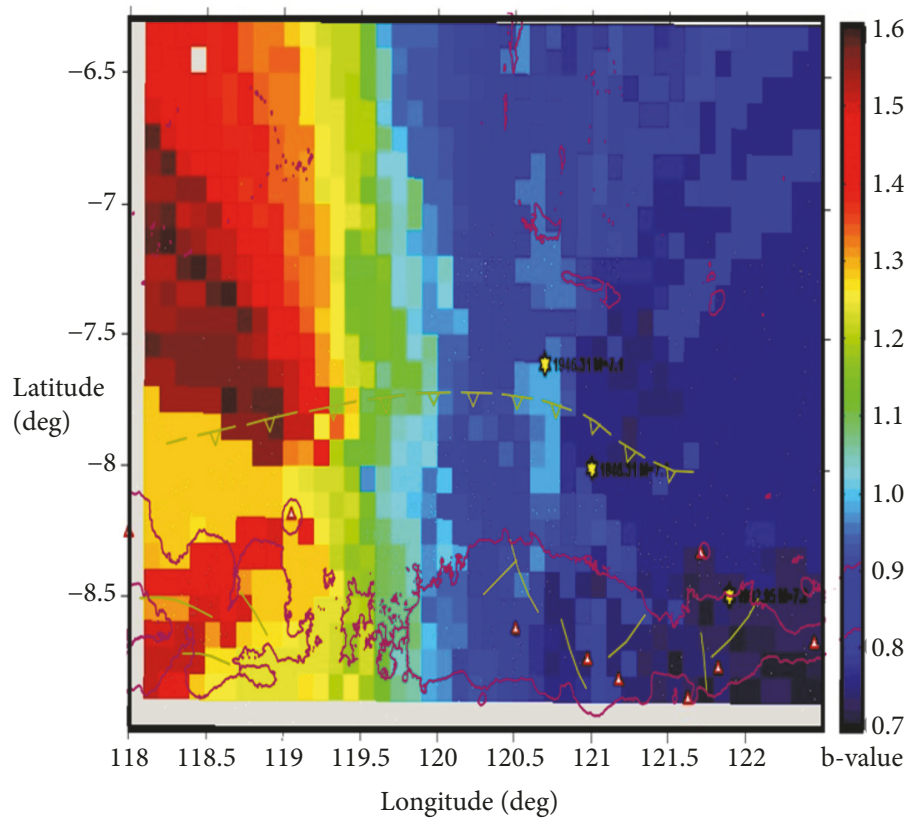

(b)

FIGURE 10: Spatial variation of seismicity of cluster 1 (Flores island, Labuan Bajo, and surrounding areas): (a) a-value and (b) b-value.

1996 and 2004. This is indicates the existence of a high level of stress on the rocks prior to the occurrence of the strong earthquakes [9].

Cluster 1 (Flores island, Labuan Bajo, and surrounding areas) can be depicted as shown in Figure 3 with earthquake number of 1,076 events, with main earthquakes of 537 incidents. After calculated using Maximum Likelihood method, it was found that the b-value is 0.89 and the a-value is 6.54 for $\mathrm{mb}>3 \mathrm{SR}$, the b-value is 1.95 and the a-value is 11.20 for $\mathrm{mb}=$ 3-5 SR, and the b-value is 0.92 and the a-value is 6.71 for $\mathrm{mb}$ $>5$ SR (Figure 9).
Based on spatial variation of seismicity, cluster 1 shows the b-values varied from 0.7 in the eastern Flores island to 1.7 in the western Labuan Bajo and surrounding areas. This implies that the Flores island to the east is categorized as high stress concentration area where weak earthquakes frequently occurred. Moreover, active volcanoes that are located in this area can trigger the occurrence of weak earthquakes. On the other hand, the west part of Flores island which has the b-value tending to be high or is called the creeping area [10] which is an active fault area does not accumulate stress (Figure 10(b)). 


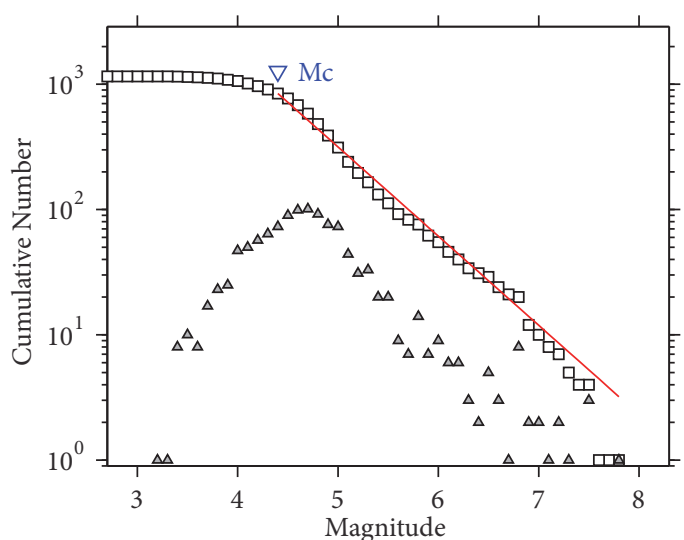

Maximum Likelihood Solution $\mathrm{b}$-value $=0.712+/-0.02$, a value $=6.06$, a value $($ annual $)=4.07$ Magnitude of Completeness $=4.4$

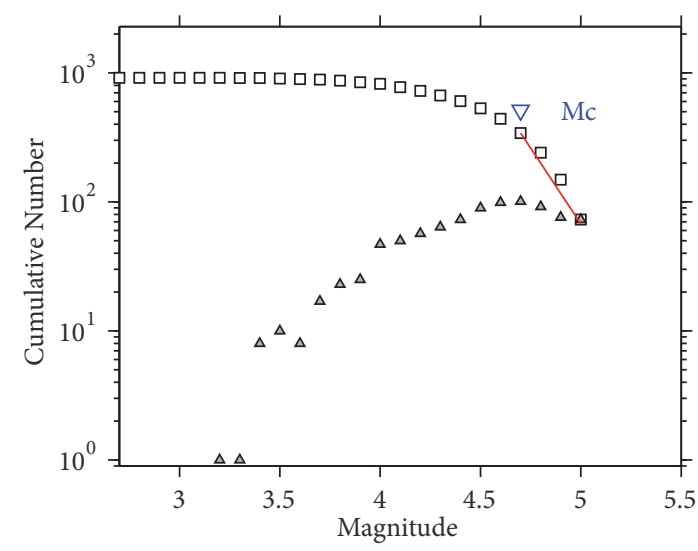

Maximum Likelihood Solution

$\mathrm{b}-$ value $=2.34+/-0.08$, a value $=13.5$, a value $($ annual $)=11.8$ Magnitude of Completeness $=4.7$

(a)

(b)

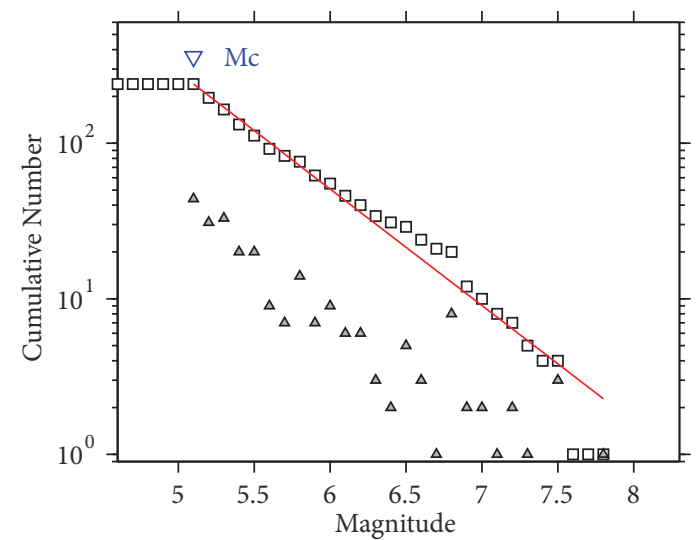

Maximum Likelihood Solution

$\mathrm{b}$-value $=0.749+/-0.05$, a value $=6.2$, a value $($ annual $)=4.21$

Magnitude of Completeness $=5.1$

(c)

FIGURE 11: Magnitude distribution graph of seismicity for cluster 2 (Timor island, Alor island, and surrounding areas): (a) for mb $>3$ SR, (b) for $m b=3-5 S R$, and (c) for $m b>5 S R$.

Cluster 2 (Timor, Alor, and surrounding areas) has 2,435 earthquake events; 1,155 of them were main earthquakes. Using Maximum Likelihood method, it was found that the $\mathrm{b}$-value is 0.712 and the a-value is 6.06 for $\mathrm{mb}>3 \mathrm{SR}$, the bvalue is 2.34 and the a-value is 13.50 for $\mathrm{mb}=3-5 \mathrm{SR}$, and the b-value is 0.749 and the a-value is 6.20 for $\mathrm{mb}>5 \mathrm{SR}$, indicating the high stress condition in this area causing a lot of weak earthquakes (Figure 11).

Based on spatial variation of seismicity, the b-value and the a-value variation in cluster 2 (Figure 12(b)) show that the Timor island and Alor islands have a low of b-value, ranging from 0.6 to 0.8 indicates rock conditions in high stress levels. This can be attributed to the large number of local fractures on Timor island and subduction zone under the Timor island [11]. The a-value variation (Figure 12(a)) ranging from 5 to 6.5 indicates a relatively insufficient tectonic state that can hold energy so that earthquakes frequently occur on a small scale.
Cluster 3 (Sumba island and surrounding areas) has 651 earthquake events, where 390 of them were the main earthquake. Using Maximum Likelihood method, it was found that the b-value is 0.87 and the a-value is 6.33 for $\mathrm{mb}$ $>3 \mathrm{SR}$, the $\mathrm{b}$-value is 1.79 and the a-value is 10.40 for $\mathrm{mb}=$ 3-5 SR, and the b-value is 0.921 and the a-value is 6.57 for $\mathrm{mb}$ $>5 \mathrm{SR}$. The low b-values indicate that the stress condition in this area is high that caused many weak earthquakes to occur (Figure 13). The existence of small earthquakes around Sumba is likely to be influenced by the local fractures that occur on the Sumba island.

Based on spatial variation of seismicity, the low b-value (0.8-0.9) was observed in the western part of Sumba island, indicating the large number of small-scale earthquakes. Meanwhile, the relatively higher b-value was found in the eastern part of Sumba island, indicating the small number of small-scale earthquakes (Figure 14). This is might occur due 


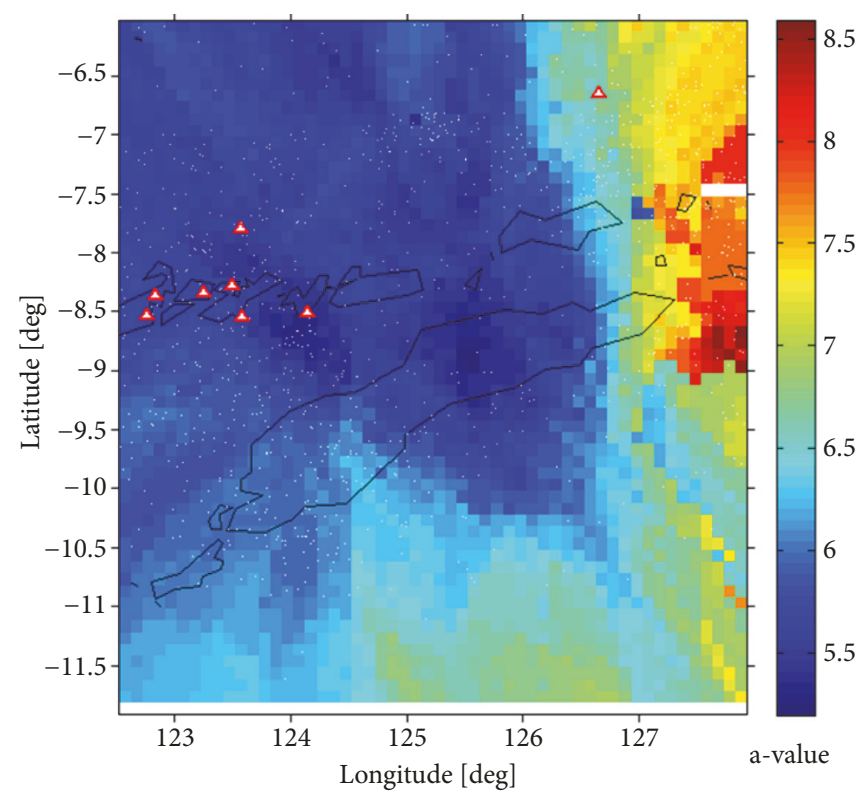

(a)

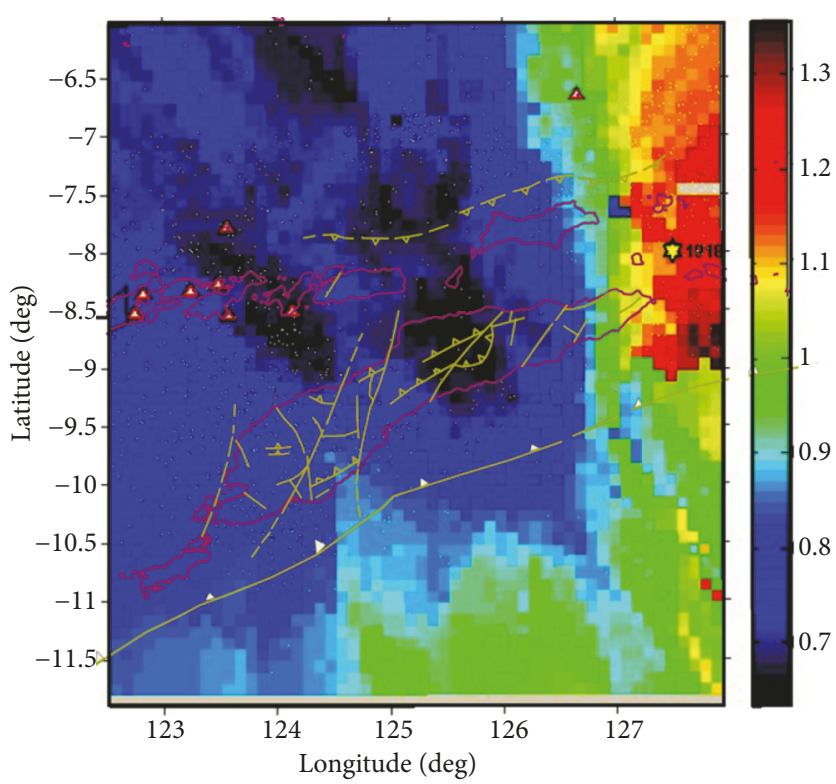

(b)

FIGURE 12: Spatial variation of seismicity of cluster 2 (Timor island, Alor island, and surrounding areas): (a) a-value and (b) b-value.

TABLE 1: The a-value and b-value and fractal dimension (D) of each cluster.

\begin{tabular}{lccc}
\hline No & Cluster & b-value & $\begin{array}{c}\text { Fractal } \\
\text { Dimension }\end{array}$ \\
\hline 1 & $\begin{array}{c}\text { Cluster 1 } \\
\text { (Flores island and } \\
\text { surrounding) }\end{array}$ & $0.837-0.937$ & 6.54 \\
\hline $\begin{array}{c}\text { Cluster 2 } \\
\text { (Timor island, Alor } \\
\text { island and } \\
\text { surrounding) }\end{array}$ & $0.692-0.732$ & 6.06 & $1.674-1.874$ \\
\hline $\begin{array}{c}\text { Cluster 3 } \\
\text { (Sumba island and } \\
\text { surrounding) }\end{array}$ & $0.852-0.932$ & 6.69 & $1.384-1.464$ \\
\hline
\end{tabular}

to presence of subduction zone in the southern part of Sumba and the fractures on the Timor island that have influence on the eastern area of Sumba island.

The a-value variation in cluster 3 shows that Sumba island and its surrounding areas have variation of value with range of $6,2-8,2$. This shows a lower level of seismic activity compared to two other clusters over a period of 75 years.

The a-value, b-value, and fractal dimensions for each cluster areas are presented in Table 1. These values are an indicator in the seismotectonic spatial distribution analysis. Based on Table 1, the three clusters show the same b-values relatively. The cluster with low b-values indicates that the area in that cluster suffers from many earthquakes. This can also be seen in the fractal dimension values that the high values of fractal dimension were observed in cluster 1 (Flores and surrounding islands) and cluster 3 (Sumba island and surrounding islands) with b-values ranges 1.674-1.874 and 1.704-1.864, respectively. In contrary, a low b-value of fractal dimension was found in cluster 2 (Timor island, Alor island, and surrounding areas), with b-value range being 1.384-1.464. Cluster 1 and cluster 3 areas most likely suffer from the return period of earthquakes in short intervals. Cluster 2, however, has a relatively longer return period of earthquakes, indicating a more irregular geometry that will result in a larger fractional coefficient in the fault system.

To illustrate the earthquake repetition that has been calculated based on the fractal value, it is calculated also based on the earthquake return period as in (8) and (10) presented in Table 2.

Table 2 shows that, in all clusters, earthquake events with $3.0 \mathrm{SR} \leq \mathrm{mb} \leq 3.9 \mathrm{SR}$ have higher seismicity index value $\left(\mathrm{N}_{1}\right)$ than earthquake occurrence with the other scale. It is also found that the earthquake with $3.0 \mathrm{SR} \leq \mathrm{mb} \leq 3.9 \mathrm{SR}$ in cluster 2 has the highest seismicity index among other regions. It means that occurrence frequency of earthquake is about 8 times a year and the return period is 0.12185 years $(44$ days). On a $4.0 \mathrm{SR} \leq \mathrm{mb} \leq 4.9 \mathrm{SR}$, cluster 2 has the highest seismicity index, 1.59285 with a return period of 0.62781 years. 


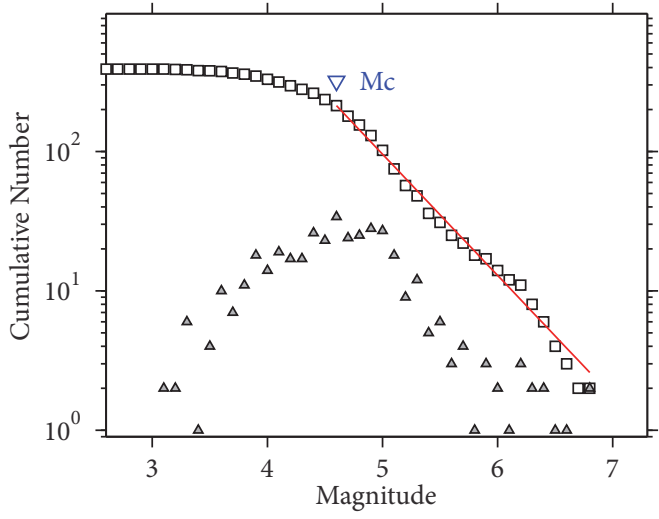

Maximum Likelihood Solution

$\mathrm{b}-$ value $=0.87+/-0.05$, a value $=6.33$, a value $($ annual $)=4.37$ Magnitude of Completeness $=4.6$

(a)

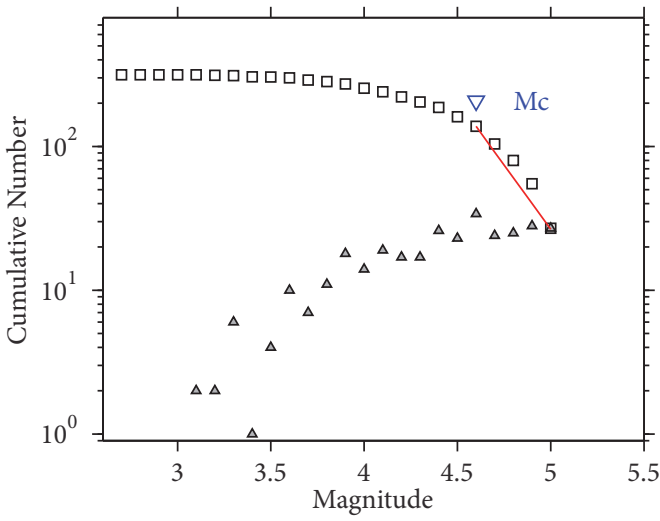

Maximum Likelihood Solution

$\mathrm{b}$-value $=1.79+/-0.09$, a value $=10.4$, a value $($ annual $)=8.7$ Magnitude of Completeness $=4.6$

(b)

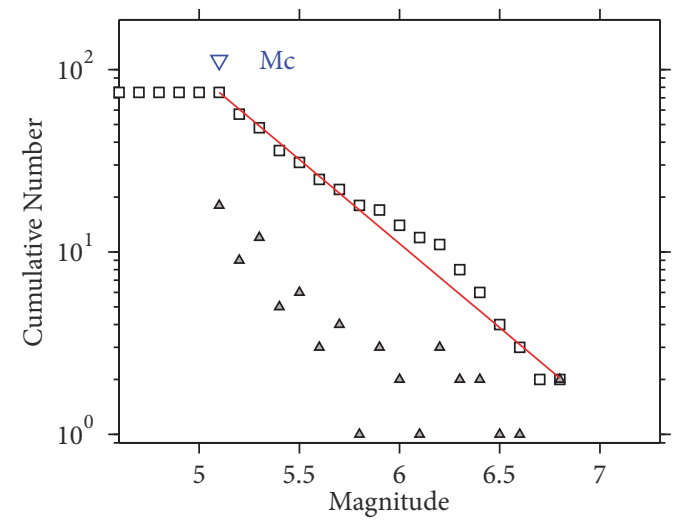

Maximum Likelihood Solution

$\mathrm{b}-$ value $=0.921+/-0.1$, a value $=6.57$, a value $($ annual $)=4.62$

Magnitude of Completeness $=5.1$

(c)

FIGURE 13: Magnitude distribution graph of seismicity for cluster 3 (Sumba island and surrounding areas): (a) for $\mathrm{mb}>3 \mathrm{SR},(\mathrm{b})$ for $\mathrm{mb}=3-5$ $\mathrm{SR}$, and $(\mathrm{c})$ for $\mathrm{mb}>5 \mathrm{SR}$.

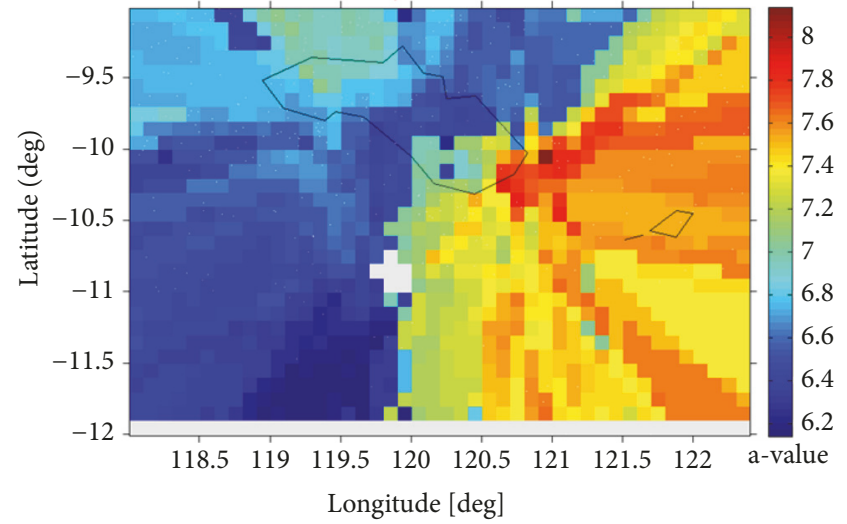

(a)

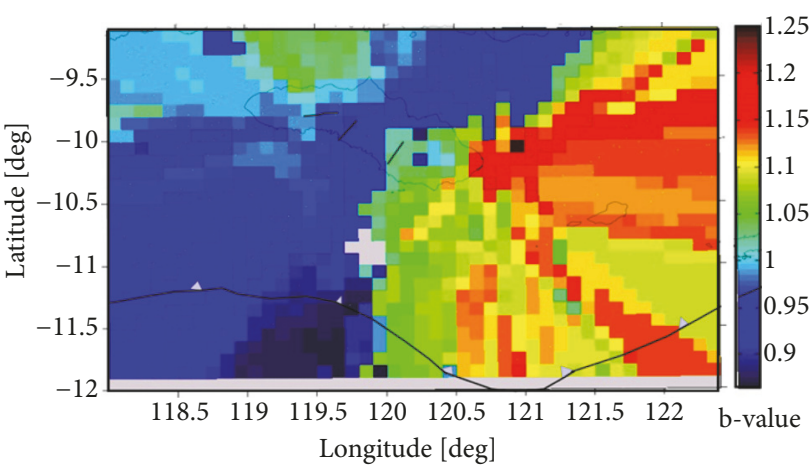

(b)

FIGURE 14: Spatial variation of seismicity of cluster 3 (Sumba island and surrounding areas): (a) a-value and (b) b-value. 
TABLE 2: Seismicity and return period of earthquake for each cluster.

\begin{tabular}{|c|c|c|c|c|c|c|c|}
\hline \multirow{2}{*}{ No } & \multirow{2}{*}{ Magnitude (Mb) (SR) } & \multicolumn{2}{|c|}{ Cluster 1} & \multicolumn{2}{|c|}{ Cluster 2} & \multicolumn{2}{|c|}{ Cluster 3} \\
\hline & & $\mathrm{N}_{1}\left(\right.$ year $\left.^{-1}\right)$ & $\theta$ (year) & $\mathrm{N}_{1}\left(\right.$ year $\left.^{-1}\right)$ & $\theta$ (year) & $\mathrm{N}_{1}\left(\right.$ year $\left.^{-1}\right)$ & $\theta$ (year) \\
\hline 1 & $3-3,9$ & 4.27339 & 0.23401 & 8.20681 & 0.12185 & 4.91215 & 0.20358 \\
\hline 2 & $4-4,9$ & 0.55433 & 1.80396 & 1.59285 & 0.62781 & 0.62990 & 1.58755 \\
\hline 3 & $5-5,9$ & 0.07191 & 13.90682 & 0.30915 & 3.23464 & 0.08077 & 12.38022 \\
\hline 4 & $6-6,9$ & 0.00933 & 107.20814 & 0.06000 & 16.66578 & 0.01036 & 96.54470 \\
\hline 5 & $7-7,9$ & 0.00121 & 826.47131 & 0.01165 & 85.86689 & 0.00133 & 752.88461 \\
\hline
\end{tabular}

Earthquake with $5.0 \mathrm{SR} \leq \mathrm{mb} \leq 5.9 \mathrm{SR}$ cluster 2 has the shortest return period of 3.23464 years, while cluster 1 and cluster 3 were 13.90682 years and 12.38022 years. Earthquakes with $\mathrm{mb}>6.0 \mathrm{SR}$ are still rare in the study area. This can be seen from the level of seismicity index and also the length of earthquake return period.

\section{Conclusion}

It can be concluded that the b-value in ENTP region is relatively low with high stress condition so that there are many weak earthquakes. This result is supported by the variation of b-value and a-value in the ENTP region, respectively, ranging from 0.6 to 1.3 and from 5.0 to 8.5 . The temporal variation in ENTP indicates that before the occurrence of big scale earthquakes, i.e., mb 7.5 SR in 1996 and 2004, there was a significant decrease in b-value. The average of the b-values ranges from 0.837 to 0.937 and the a-value is 6.54 in cluster 1 , the average of b-values ranges from 0.692 to 0.732 and a-value is 6.06 in cluster 2 , and the average of the b-value ranges from 0.852 to 0.932 and a-value is 6.69 in cluster 3 . It implies that the b-value and a-value of the clusters are not significantly different.

The result of the fractal dimension calculation shows that clusters 1,2 , and 3 have D values of 1.674-1.874, 1.3841.464 , and 1.704-1.864, respectively. Meanwhile, based on the calculation of the earthquake return period, it is found that each cluster is still dominated by small-scale earthquake with the highest seismicity index and the fastest earthquake return period is in cluster 2 which is 44 days.

\section{Data Availability}

The data used to support the findings of this study are available from the corresponding author upon request.

\section{Conflicts of Interest}

The authors declare that they have no conflicts of interest.

\section{References}

[1] W. HardjonoSatoto, "New Concept for Hydrocarbon Eploration in The "Zone C" Timor Gap and Sorrounding, Timor Sea Indonesia," in Pertemuan Ilmiah Tahunan XXX IAGI, pp. 346384, Pertamina EP, Timor Sea, Indonesia, 1996.
[2] H. M. Rosidi, S. Tjokrosapoeto, and S. Gafoer, Peta Geologi Lembar Kupang-Atambua, Timor.

[3] C. Eva, M. Cattaneo, and F. Merlanti, "Seismotectonics of the central segment of the Indonesian Arc," Tectonophysics, vol. 146, no. 1-4, pp. 241-259, 1988.

[4] D. J. Carter, M. G. Audley-Charles, and A. J. Barber, "Stratigraphical analysis of island arc-continental margin collision in eastern Indonesia," Journal of the Geological Society, vol. 132, no. 2, pp. 179-198, 1976.

[5] B. Gutenberg and C. F. Richter, "Frequency of earthquakes in California," Bulletin of the Seismological Society of America, vol. 34, pp. 185-188, 1994.

[6] T. Utsu, "A method for determining the value of b in a formula $\log \mathrm{N}=\mathrm{a} \mathrm{bM}$ showing the magnitude frequency for earthquakes," Geophysical Bulletin of the Hokkaido University, vol. 13, pp. 99-103, 1965.

[7] Y. Shi and B. A. Bolt, "The standard error of the magnitude frequency b-value," Bulletin of the Seismological Society of America, vol. 72, pp. 1677-1687, 1982.

[8] K. Aki and P. G. Richards, Quantitative Seismology, Fleeman, SF, USA, 1980.

[9] C. H. Scholz, "The frequency-magnitude relation of microfracturing in rock and its relation to earthquakes," Bulletin of the Seismological Society of America, vol. 58, pp. 399-415, 1968.

[10] S. Wiemer and M. Wyss, "Mapping spatial variability of the frequency-magnitude distribution of earthquakes," in Advances in Geophysics, R. Dmowska and B. Saltzman, Eds., vol. 45, pp. 259-302, 2002.

[11] C. E. Standley and R. Harris, "Tectonic evolution of forearc nappes of the active Banda arc-continent collision: Origin, age, metamorphic history and structure of the Lolotoi Complex, East Timor," Tectonophysics, vol. 479, no. 1-2, pp. 66-94, 2009. 

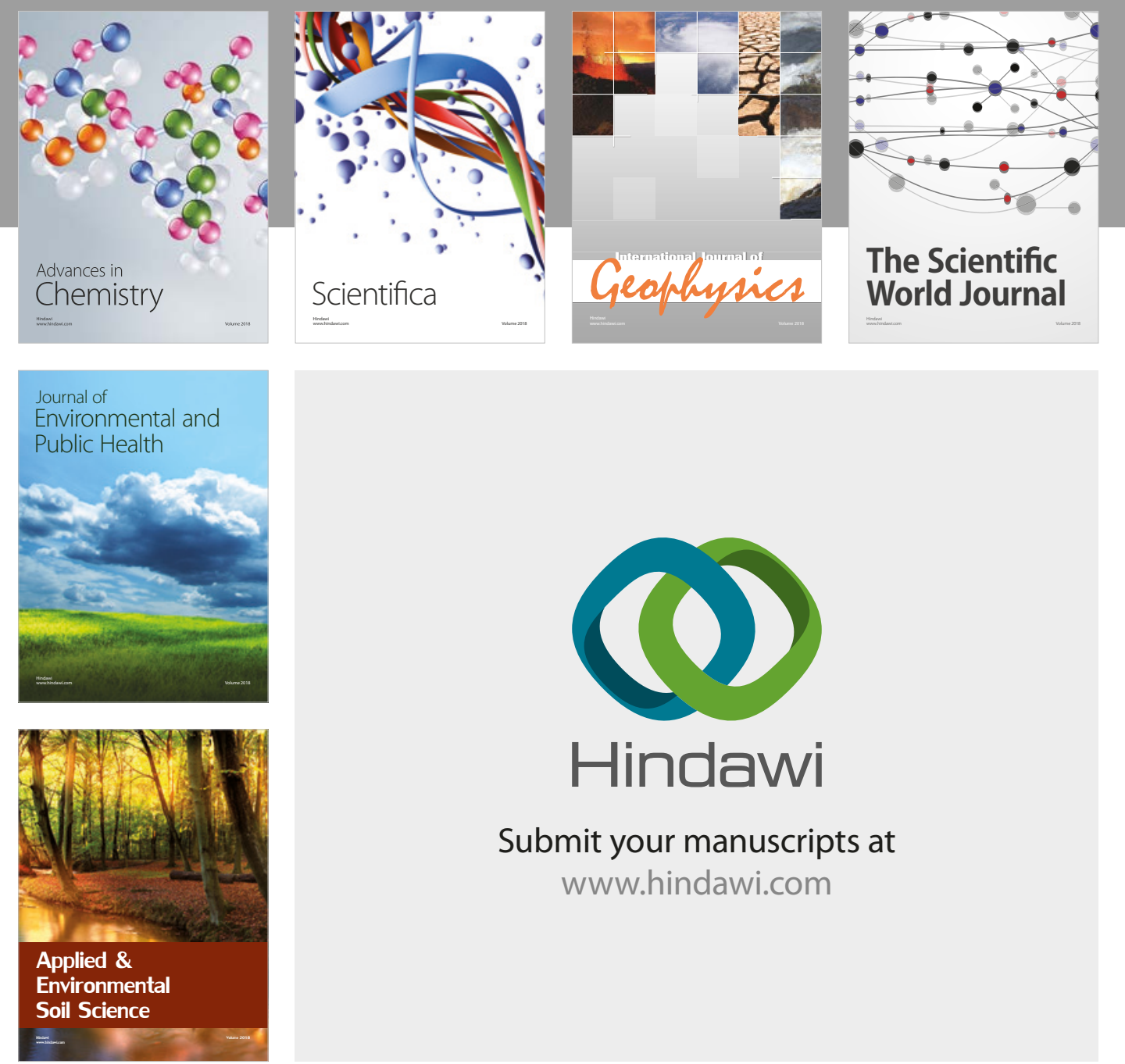

The Scientific

\section{World Journal}
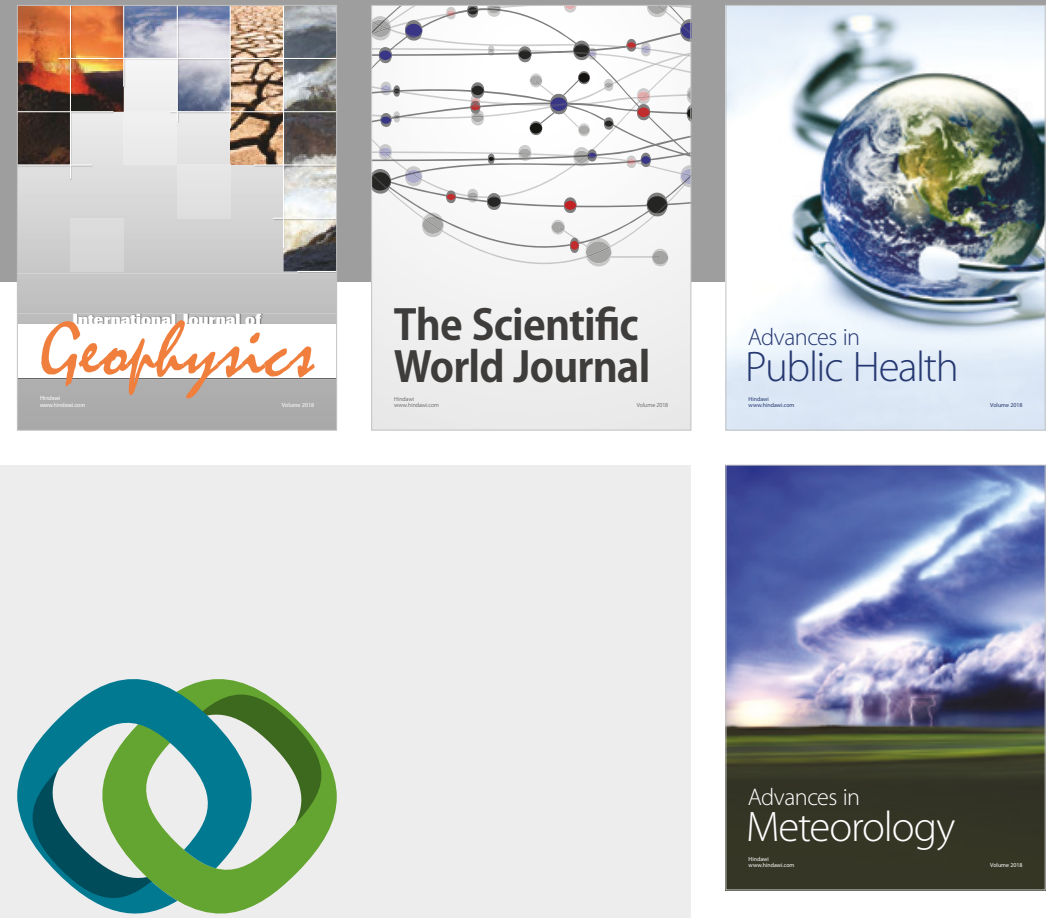

Advan

Public Health

\section{Hindawi}

Submit your manuscripts at

www.hindawi.com
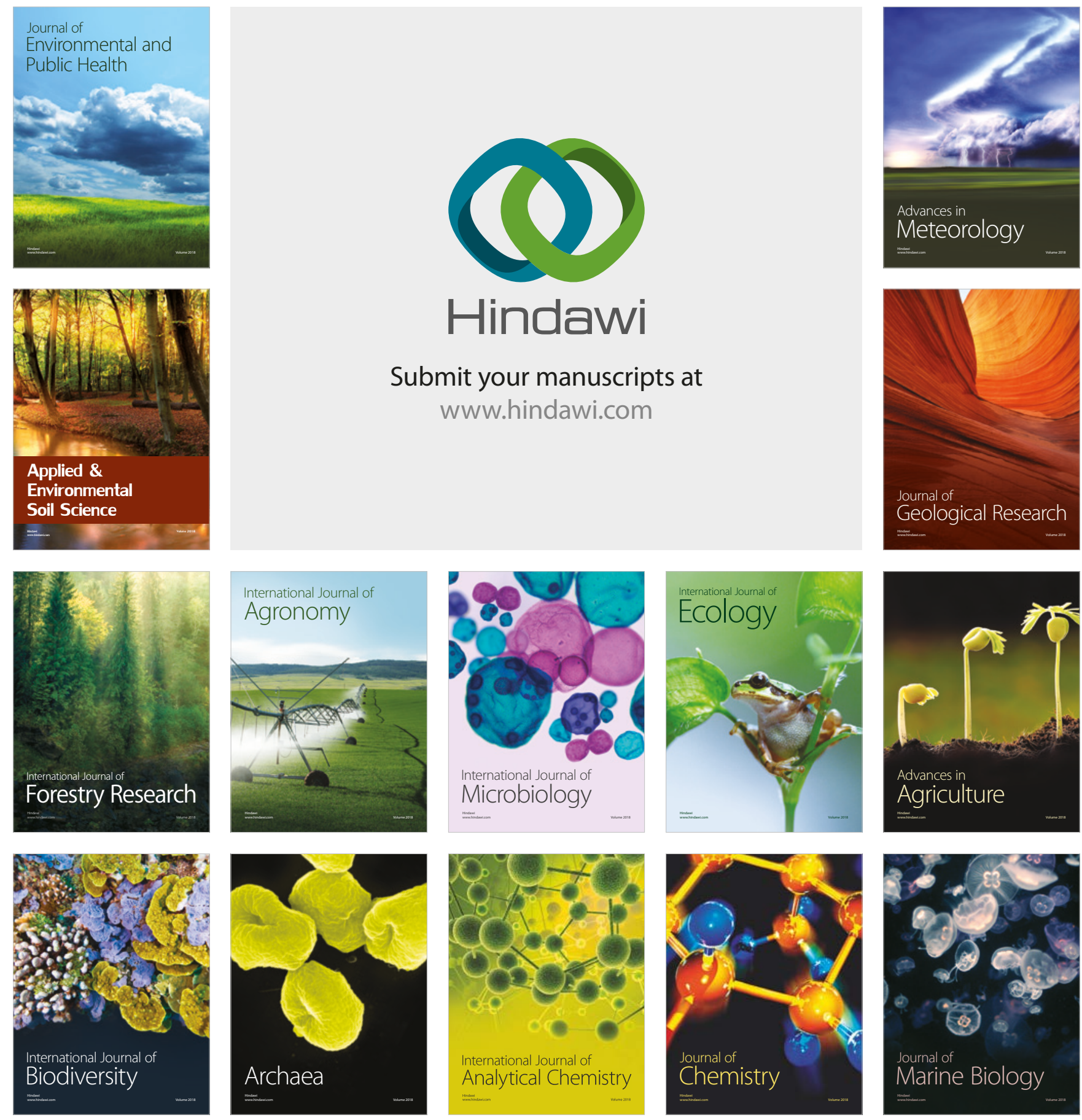